which will lessen or prevent this will prove of the utmost importance and value.

The results of the Carrel-Dakin method have been most striking and shown by:-1. The uninterrupted improvement in the general condition of the patient after resection and the rapid settling of the temperature. 2 . The very rapid obliteration of the cavity. 3. The small quantity and inoffensive nature of the discharge. 4. The firm primary anion of the sutured portions of the empyema wound.

After resecting and draining in the usual way the Dakin's solution is not at first run into the pleural cavity on account of the risk of breaking down loose adhesions, but the dressings are kept constantly moist by means of irrigation every two hours with a few ounces of the solution. The procedure here is to use a Carrel tube in the form of a horseshoe with multiple small perforations. The open ends are connected with the tube leading to the reservoir by a twoway glass connexion. The horseshoe is kept in position by being placed under the safety-pin of the drainage-tube and by being attached to the chest higher up. The surrounding skin may be protected with sterile vaseline, but in practice this is not essential, since the hypochlorite rapidly loses its tendency to irritate after contact with the discharge from the empyema. After ten days or a fortnight a Carrel tube with fow terminal perforations may be inserted into the pleural cavity alongside the dralnage-tube and irrigation every two hours with a few ounces of half-strength DakinDanfresne solution carried out.

After an extended experience of septic hæmothorax and the deleterious effects of the secondary infection after resection we have been firmly convinced of the value of the above method in lessening or almost preventing this important complication. I am, Sir, yours faithfully,

$$
\text { C. Dean, M.B. Oxon. }
$$

Millicent Sutherland Ambulance, B.E.F., April 17th, 1917.

\section{THE CLOSURE OF COLOTOMY OPENINGS.}

\section{To the Editor of The Langet.}

SIR,-Had Mr. P. Lockhart-Mummery, in his letter to THE LANCET of April 7th, confined himself to the subject of his paper I should not have troubled you with a second communication, but as he has extended his remarks to the methods of treating cancerous growths of the colon, and asks "Why are surgeons so shy of primary resections and suture of the colon that they subject their patients to three operations where one would do?" and as he goes on to say that "this seems an altogether unnecessary procedure," his attitude towards a subject of which he professes to be a master demands attention.

If he will turn to the transactions of the Surgical Section of the International Congress of Medicine held in London in 1913 he will find in the report of Professor Bastianelli and the subsequent discussion on the treatment of cancer of the colon the answer he requires. ${ }^{1}$ As this report in full may not be accessible to some of your readers I may say, briefly, that one of the most serious bars to the success of primary resection of the colon is the presence of hard frecal masses above the growth, and that this handicap can be removed by a preliminary proximal colostomy followed by washing ont the diseased segment of bowel. By this means we secure a relatively clean field for operation, while afterwards the line of union is freed from the irritation of the fæcal stream, now diverted. Again, intracolic pressure and tension on the suture line from gaseous distension are entirely obviated and rest, so essential to good union of intestinal wounds, is secured. It is worth while noting that Mr. Lockhart-Mummery, in a later paragraph in his letter, while advocating his view that the bowel should be made to act daily from the time of the resection anconsciously furnishes reasons for the multiple operation. Thus, he states that "flatus in the bowel is far more dangerous than a little liquid fæces," and, again, that "the one thing to avoid is the presence in the neighbourhood of the anastomosis of masses of hard fæces."

From a long and fairly large experience of resection of the colon with and without actual intestinal obstruction I am firmly convinced that the inclusion of a preliminary colostomy has reduced enormously the death-rate of the operation. Reverting to the original subject, Mr. LockhartMummery asserts that the Greig.Smith operation is " liable to leave a weak spot," that " many patients have to wear a belt," and that "it may be followed by stricture." My reply is that I have not seen a single instance of any one of these defects, nor do I think any of them should occur if the operation is properly done, and certainly not in the case of young soldiers with well-developed abdominal muscles. Possibly some ambiguity as to the essentials of the procedure has arisen from calling it the extraperitoneal method. Personally, as I said in my former letter, I do not dread opening the peritoneum. The one factor which makes the operation so much safer than resection of the bowel is that the mesenteric side of the colon with its vascular and nerve-supply is not interfered with.

As to details, the most important thing to attend to is to freely mobilise the opening and the adjacent colon. When this has been done the involved segment can be lifted out of the abdomen, and with adequate gauze packing it is a matter of little or no consequence whether the peritoneum is, or is not, opened. As to stricture following the operation, bearing in mind that usually at least one-half of the circumference of the bowel is not involved, and that if the sutures are inserted at right angles to the long axis of the colon the lumen is not encroached on, and that most preliminary colostomies are placed in the capacious ascending colon. there need be no fear of this developing. One word as to the spur. This formidable bugbear exists only so long as the colon is anchored to the abdominal parietes. Freely mobilise the involved segment of the bowel and the spur ceases to have any significance and enterotomes any useful application. I am, Sir, yours faithfully,

Sheffield, April 7th, 1917

SINClaIR White.

\section{READING BY EAR.}

To the Editor of THE LANCET.

SIR,-I notice in your issue of April 14th certain criticisms by Sir Arthur Pearson on the speed attainable in reading ordinary letterpress by ear with the optophone. The speed attained on March 28th was a maximum of three words a minute. My estimate of 25 words a minute was based on the fact that the signals remain clear and characteristic at that speed. It is therefore only a matter of practice. Three months ago neither I nor anybody else had ever read a line of letterpress by ear. The reading of the Times blindfold is now a possibility demonstrated beyond doubt or cavil. The instrument is substantially that described in Roy. Soc. Proc. A, 90, p. 373. - I am, Sir, yours faithfully,

E. E. FoURnier D'ALBE, D.Sc.

Maddox-street, W., April 20th, 1917.

\section{obituarp.}

\section{WILHELM WINTERNITZ.}

Wilbelm Winternitz, who died, we now learn, on Feb. 22nd at the age of 82 years, was emeritus professor of medicine in the University of Vienna and had long earned the title of the "father of scientific hydrotherapy," presiding in this capacity at the last great balneological congress held at Meran before the war. From the time of his inargural dissertation (1865) on "The Rational Basis of Certain Hyärotherapentic Measures" to the appearance, a few days before his death, of "The Water-Cure and Natural Immunity" Winternitz was constantly occupied in research on physical treatment. Many of his studies of the action of thermo-mechanical influences on the circulation and metabolism are now classical, as well as the long and bitter feud between himself and Liebermeister with regard to the bath treatment of infections diseases. His idea of determining a blood-fiux to particular organs and parts of the body was worked out in great detail long before Bier annexed the word "hyperæmia." Winternitz's belief in his own methods was very great, so that he imbued his patients with a like confidence, and he was for nearly half a century one of the busiest consultants in Vienna. But in spite of his great popularity he remained an inquirer and a research student to the last, intent on improving the field of medicine which he had so specially made his own. 